\title{
What should the optimal blood pressure goal be in patients with diabetes mellitus or chronic kidney disease?
}

Wilbert S. Aronow

Department of Medicine, Division of Cardiology, New York Medical College, Valhalla, NY, USA

Submitted: 27 May 2012

Accepted: 29 May 2012

Arch Med Sci 2012; 8, 3: 399-402

DOI: 10.5114/aoms.2012.29395

Copyright @ 2012 Termedia \& Banach

\author{
Corresponding author: \\ Wilbert S. Aronow MD \\ Cardiology Division \\ New York Medical College \\ Macy Pavilion, Room 138 \\ Valhalla, NY 10595, USA \\ Phone: (914) 493-5311 \\ Fax: (914) 235-6274 \\ E-mail: wsaronow@aol.com
}

In the absence of randomized control data, the seventh report of the Joint National Committee on Prevention, Detection, Evaluation, and Treatment of High Blood Pressure recommended that patients with diabetes mellitus or with chronic kidney disease should have their blood pressure reduced to less than $130 / 80 \mathrm{~mm} \mathrm{Hg}$ [1]. In the absence of randomized control data, the American Diabetes Association recommended that patients with diabetes mellitus and hypertension should have their blood pressure reduced to less than $130 / 80 \mathrm{~mm} \mathrm{Hg}$ [2]. In the absence of randomized control data, the National Kidney Foundation Kidney Disease Outcome Quality Initiative guidelines recommended that patients with chronic kidney disease and hypertension should have their blood pressure reduced to less than $130 / 80 \mathrm{~mm} \mathrm{Hg}$ [3]. In the absence of randomized control data, the American Heart Association 2007 guidelines recommended that patients with diabetes mellitus or with chronic kidney disease and hypertension should have their blood pressure reduced to less than $130 / 80 \mathrm{~mm} \mathrm{Hg}$ [4].

The 2009 European Society of Hypertension guidelines stated that reducing the blood pressure to less than $130 / 80 \mathrm{~mm} \mathrm{Hg}$ in patients with diabetes mellitus or chronic kidney disease and hypertension is unsupported by prospective trial data, and that the systolic blood pressure should be reduced to less than $140 \mathrm{~mm} \mathrm{Hg}$ in these patients [5]. The American College of Cardiology Foundation/American Heart Association 2011 expert consensus document on hypertension in the elderly recommended that the blood pressure should be reduced to less than $140 / 90 \mathrm{~mm} \mathrm{Hg}$ in adults younger than 80 years with diabetes mellitus or chronic kidney disease [6]. On the basis of data from the Hypertension in the Very Elderly trial [7], these guidelines recommended that the systolic blood pressure should be reduced to $140 \mathrm{~mm} \mathrm{Hg}$ to $145 \mathrm{~mm} \mathrm{Hg}$ if tolerated in adults aged 80 years and older [6]. I concur with these guidelines [5, 6, 8-13]. The following studies discuss the reasons for my recommendations.

The Pravastatin or Atorvastatin Evaluation and Infection Therapy-Thrombolysis in Myocardial Infarction (PROVE IT-TIMI) 22 trial enrolled 4,162 patients with an acute coronary syndrome (17\% with diabetes mellitus and $9 \%$ with chronic kidney disease) [14]. At 24-month follow-up, the lowest cardiovascular events rates occurred with a systolic blood pressure between $130 \mathrm{~mm} \mathrm{Hg}$ to $140 \mathrm{~mm} \mathrm{Hg}$ and a diastolic blood pressure between $80 \mathrm{~mm} \mathrm{Hg}$ to $90 \mathrm{~mm} \mathrm{Hg}$ with a nadir of $136 / 85 \mathrm{~mm} \mathrm{Hg}$ [14]. 
An observational subgroup analysis was performed in 6,400 of the 22, 576 persons enrolled in the International Verapamil SR-Trandolapril Study (INVEST) [15]. The study participants had diabetes mellitus and coronary artery disease. Persons were categorized as having tight control of their blood pressure if they could maintain their systolic blood pressure below $130 \mathrm{~mm} \mathrm{Hg}$ and their diastolic blood pressure below $85 \mathrm{~mm} \mathrm{Hg}$, usual control if they could maintain their systolic blood pressure between $130 \mathrm{~mm} \mathrm{Hg}$ to $139 \mathrm{~mm} \mathrm{Hg}$, and uncontrolled if their systolic blood pressure was $140 \mathrm{~mm} \mathrm{Hg}$ or higher.

During 16,893 patient-years of follow-up, a cardiovascular event rate of $12.6 \%$ occurred in patients with usual control of blood pressure versus $19.8 \%$ in patients with uncontrolled hypertension, $p<0.001$ [15]. The incidence of cardiovascular events was $12.6 \%$ in patients with usual control of blood pressure vs. $12.7 \%$ in patients with tight control of blood pressure ( $p$ not significant). The all-cause mortality rate was $11.0 \%$ with tight control of blood pressure vs. $10.2 \%$ with usual control of blood pressure $(p=0.06)$. When extended follow-up to 5 years following the close of INVEST was included, the all-cause mortality rate was $22.8 \%$ with tight control of blood pressure vs. $21.8 \%$ with usual control of blood pressure, $p=0.04$ [15].

The Action to Control Cardiovascular Risk in Diabetes (ACCORD ) blood pressure trial randomized 4,733 persons with type 2 diabetes mellitus to intensive blood pressure control with a target systolic blood pressure of $<120 \mathrm{~mm} \mathrm{Hg}$ or to standard blood pressure control with a target systolic blood pressure $<140 \mathrm{~mm} \mathrm{Hg}$ [16]. The primary composite outcome was nonfatal myocardial infarction, nonfatal stroke, or death from cardiovascular causes. Mean follow-up was 4.7 years. After 1 year, the mean systolic blood pressure was $119.3 \mathrm{~mm} \mathrm{Hg}$ in the intensive blood pressure control group vs. $133.5 \mathrm{~mm} \mathrm{Hg}$ in the standard blood pressure control group. The annual rate of the primary outcome was $1.87 \%$ in the intensive blood pressure control group vs. $2.09 \%$ in the standard blood pressure control group ( $p$ not significant) [16]. The annual rate of death from any cause was $1.28 \%$ in the intensive blood pressure control group vs. $1.19 \%$ in the standard blood pressure control group ( $p$ not significant). The annual rate of death from cardiovascular causes was $0.52 \%$ in the intensive blood pressure control group vs. $0.49 \%$ in the standard blood pressure control group ( $p$ not significant). The annual stroke rate, a prespecified secondary outcome, was $0.32 \%$ in the intensive blood pressure control group vs. $0.53 \%$ in the standard blood pressure control group, $p=0.01$ (number needed to treat to reduce 1 stroke $=476$ patients). Serious adverse events attributed to antihypertensive treatment occurred in $3.3 \%$ of the intensive blood pressure control group vs. $1.3 \%$ of the standard blood pressure control group $(p<0.001)$ [16].

The ONgoing Telmisartan Alone and in combination with Ramipril Global Endpoint Trial (ONTARGET) included 9,603 diabetics, mean age 66.1 years, and 15,981 nondiabetics, mean age 66.6 years, with hypertension at high risk for cardiovascular events [17]. The primary outcome was a composite of cardiovascular death, nonfatal myocardial infarction, nonfatal stroke, or hospitalization for heart failure. Mean follow-up was 4.6 years. Compared with nondiabetics, diabetics had a $48 \%$ significant increase in the primary endpoint, a $56 \%$ significant increase in cardiovascular death, a 30\% significant increase in myocardial infarction, a 39\% significant increase in stroke, and a $206 \%$ significant increase in hospitalization for congestive heart failure [17].

In both diabetics and nondiabetics, antihypertensive drug treatment reduced the primary outcome if the baseline systolic blood pressure was between $143 \mathrm{~mm} \mathrm{Hg}$ to $155 \mathrm{~mm} \mathrm{Hg}$ [17]. Except for stroke, there was no benefit in reducing fatal or nonfatal cardiovascular outcomes by reducing the systolic blood pressure below $130 \mathrm{~mm} \mathrm{Hg}$ in diabetics and in nondiabetics. The lowest incidence of death from cardiovascular causes in diabetics occurred with a systolic blood pressure of $135.6 \mathrm{~mm} \mathrm{Hg}$ (range $130.6 \mathrm{~mm} \mathrm{Hg}$ to $140.5 \mathrm{~mm} \mathrm{Hg}$ ). The lowest incidence of death from cardiovascular causes in nondiabetics occurred with a systolic blood pressure of $133.1 \mathrm{~mm} \mathrm{Hg}$ (range $128.8 \mathrm{~mm} \mathrm{Hg}$ to $137.4 \mathrm{~mm} \mathrm{Hg}$ ). For the primary outcome, the highest risk in both diabetics and in nondiabetics occurred in patients with the lowest or highest intrial diastolic blood pressure $(67.2 \mathrm{~mm} \mathrm{Hg}$ and $86.7 \mathrm{~mm} \mathrm{Hg}$, respectively) [17].

The mean systolic blood pressure was $144 \mathrm{~mm} \mathrm{Hg}$ in both the intensively treated diabetics in the United Kingdom Prospective Diabetes Study [18] and in the post hoc subgroup analysis of the Hypertension Optimal Treatment trial [19]. The mean systolic blood pressure was $135 \mathrm{~mm} \mathrm{Hg}$ in the intensively treated diabetics in the Action in Diabetes and Vascular Disease: Preterax and Diamicron Modified Release Controlled Evaluation (ADVANCE study) [20].

A meta-analysis was performed which included the 2,272 patients with hypertensive chronic kidney disease without diabetes mellitus in the African American Study of Kidney Disease and Hypertension (AASK) [21], the Modification of Diet in Renal Disease (MDRD) [22], and the Ramipril Efficacy in Nephropathy 2 (REIN-2) [23] trials [24]. This meta-analysis showed that a blood pressure of less than $125 / 75 \mathrm{~mm} \mathrm{Hg}$ to $130 / 80 \mathrm{~mm} \mathrm{Hg}$ did not improve clinical outcomes more than a tar- 
get blood pressure of less than 140/90 $\mathrm{mm} \mathrm{Hg}$ [24]. Whether a blood pressure of less than $130 / 80 \mathrm{~mm} \mathrm{Hg}$ benefits patients with proteinuria greater than 300 to $1,000 \mathrm{mg}$ per day requires further study [24].

Intensive lowering of blood pressure also does not improve clinical outcomes in patients with a recent noncardioembolic stroke [25] or with heart failure [26]. On the basis of the available data, the blood pressure in patients with hypertension at high risk for cardiovascular events because of coronary artery disease, diabetes mellitus, chronic kidney disease, stroke, or heart failure should be reduced to less than $140 / 90 \mathrm{~mm} \mathrm{Hg}$ in patients younger than 80 years and the systolic blood pressure reduced to 140 to $145 \mathrm{~mm}$ hg if tolerated in patients aged 80 years and older [6].

\section{Acknowledgments}

This topic will be presented as a talk at the Annual Scientific Meeting of the American Society of Nephrology on October 31, 2012 in San Diego, California.

\section{References}

1. Chobanian AV, Bakris GL, Black HR, et al. The Seventh Report of the Joint National Committee on Prevention, Detection, Evaluation, and Treatment of High Blood Pressure. The JNC 7 Report. JAMA 2003; 289: 2560-72.

2. American Diabetes Association. Standards of medical care for patients with diabetes mellitus. Diabetes Care 2003; 26 (Suppl 1): S33-50.

3. National Kidney Foundation. K/DOQI clinical practice guidelines for chronic kidney disease: evaluation, classification, and stratification. Am J Kidney Dis 2002; 39 (Suppl 1): S1-266.

4. Rosendorff C, Black HR, Cannon CP, et al. Treatment of hypertension in the prevention and management of ischemic heart disease. A scientific statement from the American Heart Association Council for High Blood Pressure Research and the Councils on Clinical Cardiology and Epidemiology and Prevention. Circulation 2007; 115: 2761-88.

5. Mancia G, Laurent S, Agabiti-Rosei E, et al. Reappraisal of European guidelines on hypertension management: a European Society of Hypertension Task Force document. Blood Press 2009; 18: 308-47.

6. Aronow WS, Fleg JL, Pepine CJ, et al. ACCF/AHA 2011 expert consensus document on hypertension in the elderly: a report of the American College of Cardiology Foundation Task Force on Clinical Expert Consensus Documents. Developed in collaboration with the American Academy of Neurology, American Geriatrics Society, American Society for Preventive Cardiology, American Society of Hypertension, American Society of Nephrology, Association of Black Cardiologists, and European Society of Hypertension. J Am Coll Cardiol 2011; 57: 2037-114.

7. Beckett NS, Peters R, Fletcher AE, et al. Treatment of hypertension in patients 80 years of age or older. $\mathrm{N}$ Eng J Med 2008; 358: 1887-98.

8. Aronow WS. Editorial on management of diabetes mellitus with coronary artery disease. Arch Med Sci 2011; 6: 928-30.
9. Aronow WS. Hypertension guidelines. Hypertension 2011; 58: 347-8.

10. Banach M, Michalska M, Kjeldsen SE, et al. What should be the optimal levels of blood pressure: does the J-curve phenomenon really exist? Expert Opin Pharmacother 2011; 12: 1835-44.

11. Banach M, Aronow WS. Should we have any doubts about hypertension therapy in elderly patients. ACCF/AHA 2011 expert consensus document on hypertension in the elderly. Pol Arch Med Wewn 2011; 121: 253-8.

12. Aronow WS, Banach M. Ten most important things to learn from the ACCF/AHA 2011 expert consensus document on hypertension in the elderly. Blood Pressure 2012; 21: 3-5.

13. Banach M, Aronow WS. Hypertension therapy in the elderly-do we know the answers to all the questions? The status after publication of the ACCF/AHA 2011 Expert Consensus Document on Hypertension in the Elderly. J Hum Hypertens in press.

14. Bangalore S, Qin J, Sloan S, et al. What is the optimal blood pressure in patients after acute coronary syndromes? Relationship of blood pressure and cardiovascular events in the Pravastatin or Atorvastatin Evaluation and Infection Therapy-Thrombolysis in Myocardial Infarction (PROVE IT-TIMI) 22 trial. Circulation 2010; 122: 2142-51.

15. Cooper-DeHoff RM, Gong Y, Handberg EM, et al. Tight blood pressure control and cardiovascular outcomes among hypertensive patients with diabetes and coronary artery disease. JAMA 2010; 304: 61-8.

16. The ACCORD Study Group. Effects of intensive bloodpressure control in type 2 diabetes mellitus. N Engl J Med 2010; 362: 1575-85.

17. Redon J, Mancia G, Sleight P, et al. Safety and efficacy of low blood pressures among patients with diabetes. Subgroup analyses from the ONTARGET (ONgoing Telmisartan Alone and in combination with Ramipril Global Endpoint Trial). J Am Coll cardiol 2012; 59: 74-83.

18. UK Prospective Diabetes Study Group. Tight blood pressure control and risk of macrovascular and microvascular complications in type 2 diabetes: UKPDS38. BMJ 1998; 317: 703-13.

19. Hansson L, Zanchetti A, Carruthers SG, et al. Effects of intense blood pressure lowering and low dose aspirin in patients with hypertension: principal results of the Hypertension Optimal Treatment (HOT) randomized trial. Lancet 1998; 351: 1755-62.

20. Patel A, ADVANCE Collaborative Group, MacMahon S, et al. Effects of a fixed combination of perindopril and indapamide on macrovascular and microvascular outcomes in patients with type 2 diabetes mellitus (the ADVANCE trial): a randomised controlled trial. Lancet 2007; 370: 829-40.

21. Appel LJ, Wright JT Jr, Greene T, et al. Intensive bloodpressure control in hypertensive chronic kidney disease. N Engl J Med 2010; 363: 918-29.

22. Lazarus JM, Bourgoignie JJ, Buckalew VM, et al. Achievement and safety of a low blood pressure goal in chronic renal disease: the Modification of Diet in Renal Disease Study Group. Hypertension 1997; 29: 641-50.

23. Ruggenenti P, Perna A, Loriga G, et al. Blood-pressure control for renoprotection in patients with nondiabetic chronic renal disease (REIN-2): multicentre, randomised controlled trial. Lancet 2005; 365: 939-46.

24. Upadhyay A, Earley A, Haynes SM, Uhlig K. Systematic review: blood pressure target in chronic kidney disease 
and proteinuria as an effect modifier. Ann intern Med 2011; 154: 541-8.

25. Ovbiagele B, Diener HC, Yusuf S, et al. Level of systolic blood pressure within the normal range and risk of recurrent stroke. JAMA 2011; 306: 2137-44.

26. Banach M, Bhatia V, Feller MA, et al. Relation of baseline systolic blood pressure and long-term outcomes in ambulatory patients with chronic mild to moderate heart failure. Am J Cardiol 2011; 107: 1208-14. 